\title{
The pyranine-benzalkonium ion pair: a promising fluorescent system for the ratiometric detection of wound $\mathrm{pH}$
}

Guido Panzarasa $^{\ddagger \mathrm{a}}$, Alina Osypova ${ }^{\mathrm{a}}$, Claudio Toncelli ${ }^{\mathrm{a}}$, Matthias T. Buhmann ${ }^{\mathrm{b}}$, Markus Rottmar $^{\mathrm{b}}$, Qun Ren ${ }^{\mathrm{b}}$, Katharina Maniura-Weber ${ }^{\mathrm{b}}$, René M. Rossi ${ }^{\mathrm{a}}$, Luciano F. Boesel ${ }^{\mathrm{a} *}$

\$These authors contributed equally.

*Corresponding author. E-mail: luciano.boesel@empa.ch

aEmpa, Swiss Federal Laboratories for Materials Science and Technology, Laboratory for Biomimetic Membranes and Textiles, Lerchenfeldstrasse 5, CH-9014 St. Gallen, Switzerland

${ }^{b}$ Empa, Swiss Federal Laboratories for Materials Science and Technology, Biointerfaces, Lerchenfeldstrasse 5, CH-9014 St. Gallen, Switzerland

\begin{abstract}
Pyranine is a non-toxic fluorescent dye, with a broad range of applications in biomedicine where it allows precise ratiometric detection of $\mathrm{pH}$ within the physiological $\mathrm{pH}$ window. Hereby, the facile synthesis, potentially interesting for commercial applications, of a novel ion pair between pyranine and benzalkonium is described. Benzalkonium, a quaternary ammonium salt with potent antimicrobial properties, makes pyranine sufficiently hydrophobic to allow its incorporation in conventional membranes and commercial wound dressings while maintaining its $\mathrm{pH}$ sensing performance unaffected. In conclusion, this novel fluorescent ion pair could be extremely promising for the non-invasive monitoring of wound $\mathrm{pH}$.

This document is the accepted manuscript version of the following article: Panzarasa, G., Osypova, A., Tonce11i, C., Buhmann, M. T., Rottmar, M., Ren, Q., ... Boese1, L. F. (2017). The pyranine-benzalkonium ion pair: a promising fluorescent system for the ratiometric detection of wound pH. Sensors and Actuators B: Chemical, 249, 156-160. https://doi.org/10.1016/j.snb.2017.04.045

This manuscript version is made available under the CC-BY-NC-ND 4.0 1icense http:// creativecommons.org/1icenses/by-nc-nd/4.0
\end{abstract}




\section{Table of Contents graphic}

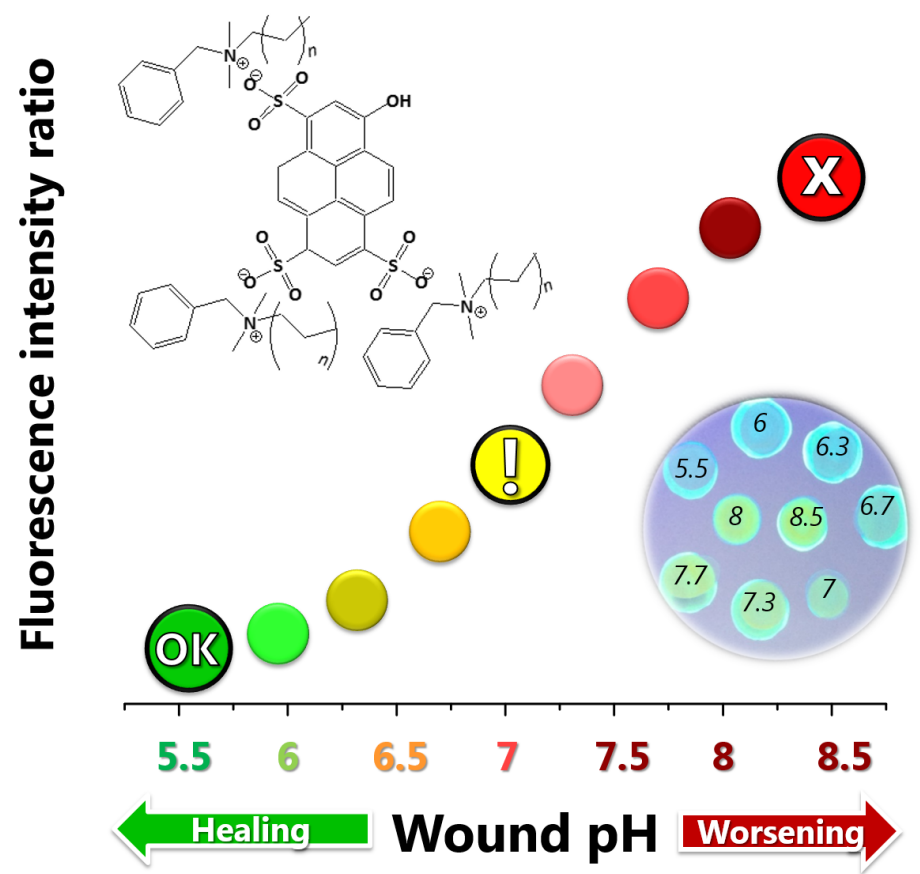

\section{HIGHLIGHTS}

- A novel hydrophobic ion pair of pyranine and benzalkonium is described.

- The pyranine-benzalkonium ion pair is suitable for the ratiometric fluorescent detection of wound $\mathrm{pH}$.

- Ease of synthesis, the use of intrinsically non-toxic and commercially interesting precursors and antimicrobial properties make the ion pair appealing for biomedical applications.

\section{KEYWORDS}

Pyranine, benzalkonium chloride, $\mathrm{pH}$ sensing, ratiometric, chronic wound monitoring, antimicrobial 


\section{INTRODUCTION}

Chronic wounds are a costly healthcare issue and are of increasing relevance especially in countries with ageing populations [1]. This generates a demand to improve the quality and performance of wound dressings, which would make wound care easier, more comfortable for the patient, and more cost-effective for healthcare providers. The current practice for wound care involves the manual removal of a dressing for visual inspection of the underlying wound and the sampling of exudate for ex vivo measurements. These are not only time-consuming tasks for the nursing staff, but more importantly, they are painful for the patient and disturb the natural healing process of the wound, moreover increasing the risk of infections. Novel concepts for improved wound dressings allow in situ sensing of wound parameters (including temperature, moisture, oxygenation and $\mathrm{pH}$ ), alerting medical staff to the possible presence of infection and other healing characteristics without the need to remove the dressing [2,3]. Such smart dressings, in turn, have the potential to generate significant savings in healthcare costs thanks to reduced clinical inspection time and shorter hospital stays as a result of faster wound healing. Of course, these new dressings must also need to be reasonably cheap, as high costs would greatly limit their acceptance by clinicians.

Of all the parameters of interest for the chronic wound, $\mathrm{pH}$ has been indicated as the most determinant $[4,5]$. While the natural $\mathrm{pH}$ of the skin may vary from person to person, it typically fluctuates within a narrow acidic range between $\mathrm{pH} 4$ and $\mathrm{pH}$, which helps to control bacterial proliferation. Whenever an injury generates a cutaneous wound, it exposes the underlying tissue, which, as it is normally regulated at $\mathrm{pH} 7.4$, can encourage bacterial adhesion and proliferation and thereby promote infection. The $\mathrm{pH}$ of the chronic wound, however, oscillates in a weakly alkaline range between $\mathrm{pH} 7$ and $\mathrm{pH} 8$, increasing the susceptibility towards bacterial infestation [6]. Such increase in $\mathrm{pH}$ has been proposed as a diagnostic tool to identify the onset of an infection [7]. Consequently, there is an increasing effort to develop disposable $\mathrm{pH}$ sensors for non-invasive wound monitoring.

To this end, pH-sensitive colorimetric dyes were the first obvious candidates to be chosen. However, since sensors based on light absorbance are not as sensitive as those based on fluorescence, $\mathrm{pH}$-sensitive fluorometric dyes rapidly became the most studied. Depending on the $\mathrm{pH}$, some fluorescent dyes possess different absorption maxima due to differences in their acidic (protonated) and basic (deprotonated) forms. While the emission intensity is dependent on the excitation wavelength, the emission maxima is usually unaffected by $\mathrm{pH}$. Thus, it is possible to measure the emission intensities at two excitation wavelengths, and the ratio of the emission intensities becomes a function of $\mathrm{pH}$. Such a "dual excitation"-“single emission" measurement 
process is a highly reliable method for the determination of $\mathrm{pH}$ since it minimizes the impact of detrimental factors such as fluorophore concentration, photobleaching, excitation light intensity fluctuation and detector sensitivity. Examples of dyes exhibiting this kind of behavior include carboxydichlorofluorescein (CDCF), carboxynaphthofluorescein (CNF) and 8-hydroxypyrene1,3,6-trisulfonic acid (HPTS, pyranine) [8].

We have recently developed chemical and bio-sensors based on fluorescein derivatives (CNF and fluorescein isothiocyanate FITC) for different applications. pH sensors were constructed by incorporating a FRET-forming dye pair into xerogel matrices [9,10], where FITC was used either as donor or acceptor. The system exhibited good reversibility and could be used as coating for a range of substrates, including plates, optical fibers, and textiles $[9,10]$. Based on that system, we developed a simpler one, containing $\mathrm{CNF}$ as single dye as a potential $\mathrm{pH}$ sensor for chronic wounds [11]. Another derivative, 2',7'-dichlorofluorescein-diacetate (H2DCF-DA), was combined with a coupled enzymatic assay to function as a bio-sensor to e.g., glucose in the wound exudate [11]. However, these three systems are intensity-based and thus prone to the disadvantages mentioned above.

In the present work, we turned our attention to HPTS: it is a hydrophilic, pH-sensitive fluorescent dye with very good photostability (a property shared also by its derivatives) [12] and a broad range of applications for optical sensors [13-20]. HPTS has also been used for various biological applications, e.g. for the measurement of intracellular $\mathrm{pH}$, thanks to its high water solubility and low toxicity [21,22]. In addition to all these favorable properties, HPTS has two different, pH-dependent, excitation wavelengths (at $\sim 405$ and $\sim 460 \mathrm{~nm}$, respectively) which correspond to an emission at $\sim 514 \mathrm{~nm}$. The $\mathrm{pH}$ sensitivity of HPTS arises from the $\mathrm{OH}$ group placed in the position $8^{\prime}$, whose $\mathrm{pK}_{\mathrm{a}}=7.3$ corresponds to a $\mathrm{pH}$ calibration range ranging from $\mathrm{pH}$ $\sim 6$ to $\sim 9$, adequate for biological applications and especially suitable for the monitoring of $\mathrm{pH}$ as bio-marker of the wound status.

However, a significant drawback for the application of HPTS in aqueous environments is its high solubility in water. To overcome this problem, we exploited the strategy originally developed by Wolfbeis [23], in which alkali counterions of hydrophilic dyes are replaced by quaternary ammonium groups with long aliphatic alkyl chains by reacting them with the respective bromide or chloride to form a lipophilic ion pair. Such an approach has been extensively used to make indicator dyes sufficiently hydrophobic to allow their incorporation into polymer and sol-gel matrices. Tetrabutylammonium bromide (TBAB), tetraoctylammonium bromide (TOAB) and especially cetyltrimethylammonium bromide $(\mathrm{CTAB})$ have been the most used quaternary ammonium to form a lipophilic ion pair [23]. 
Benzalkonium chloride (BZKC) is a quaternary ammonium compound with relevant industrial applications as a biocide, as a cationic surfactant and as a phase transfer agent. BZKC is used as a disinfectant, detergent, and antiseptic. The mechanism of its bactericidal effect is thought to be the disruption of intermolecular interactions, which eventually cause the dissociation of cellular membrane bilayers. Because of its broad range of antimicrobial activity and its nontoxicity, it is the preservative of choice for most multiuse aqueous nasal, ophthalmic, and otic products. It is used in hand sanitizers, first aid products (to prevent infection in minor scrapes and cuts), leave-on skin antiseptics, hygienic wet wipes, and disinfectant solutions for both clinical and household use [24-26]. Moreover, it has been demonstrated that BZKC still retains its antimicrobial properties when incorporated, also by ion pairing, into different matrices [27,30].

Here we report the use of benzalkonium chloride to make form a hydrophobic ion pair with pyranine with double features as $\mathrm{pH}$ sensor and antimicrobial coating and we demonstrate its suitability as a fluorescent system for the ratiometric detection of wound $\mathrm{pH}$.

\section{RESULTS AND DISCUSSION}

Synthesis and characterization of the pyranine-benzalkonium (HPTS-BZK) ion pair

The synthesis of the pyranine-benzalkonium ion pair was attained by mixing aqueous solutions of the dye and of the quaternary ammonium in a 1:3 molar ratio, as shown in equation 1:

$$
\mathrm{HPTS}^{3-}\left(\mathrm{Na}^{+}\right)_{3}+3 \mathrm{BZK}^{+} \mathrm{Cl}^{-} \rightarrow \mathrm{HPTS}^{3-}\left(\mathrm{BZK}^{+}\right)_{3}+\mathrm{NaCl}
$$

A detailed description of the synthetic methodology can be found in the Supporting Information.

Figure 1A shows the ATR-FTIR spectra of three different samples, namely: pure HPTS, pure BZKC and the resulting ion pair. The most relevant absorption bands and peaks are: 3700$3000 \mathrm{~cm}^{-1}$, OH stretching (for all the three samples); $3000-2780 \mathrm{~cm}^{-1}, \mathrm{CH}_{2}$ and $\mathrm{CH}_{3}$ stretching (BZKC and HPTS-BZK); 1480-1430 $\mathrm{cm}^{-1}, \mathrm{CH}_{2}$ and $\mathrm{CH}_{3}$ bending (BZKC and HPTS-BZK); 1250$1100 \mathrm{~cm}^{-1}, \mathrm{~S}=\mathrm{O}$ stretching (HPTS and HPTS-BZK); 1100-1000 $\mathrm{cm}^{-1}, \mathrm{SO}_{3}{ }^{-}$stretching (HPTS and HPTS-BZK); $1000 \mathrm{~cm}^{-1}$, C-N stretching (BZKC) [27,28]. The formation of an actual ion pair between HPTS and BZK, rather than simply having a physical mixture, is demonstrated by the broadening of the $\mathrm{S}=\mathrm{O}$ stretching band and by the blue shift of the $\mathrm{SO}_{3}{ }^{-}$stretching peaks $\left(1010 \mathrm{~cm}^{-1}\right.$ vs $1005 \mathrm{~cm}^{-1}, 1046 \mathrm{~cm}^{-1}$ vs $1035 \mathrm{~cm}^{-1}, 1073 \mathrm{~cm}^{-1}$ vs $1056 \mathrm{~cm}^{-1}$ for HPTS and HPTS-BZK, respectively) (Figure 1B) [27,28]. 

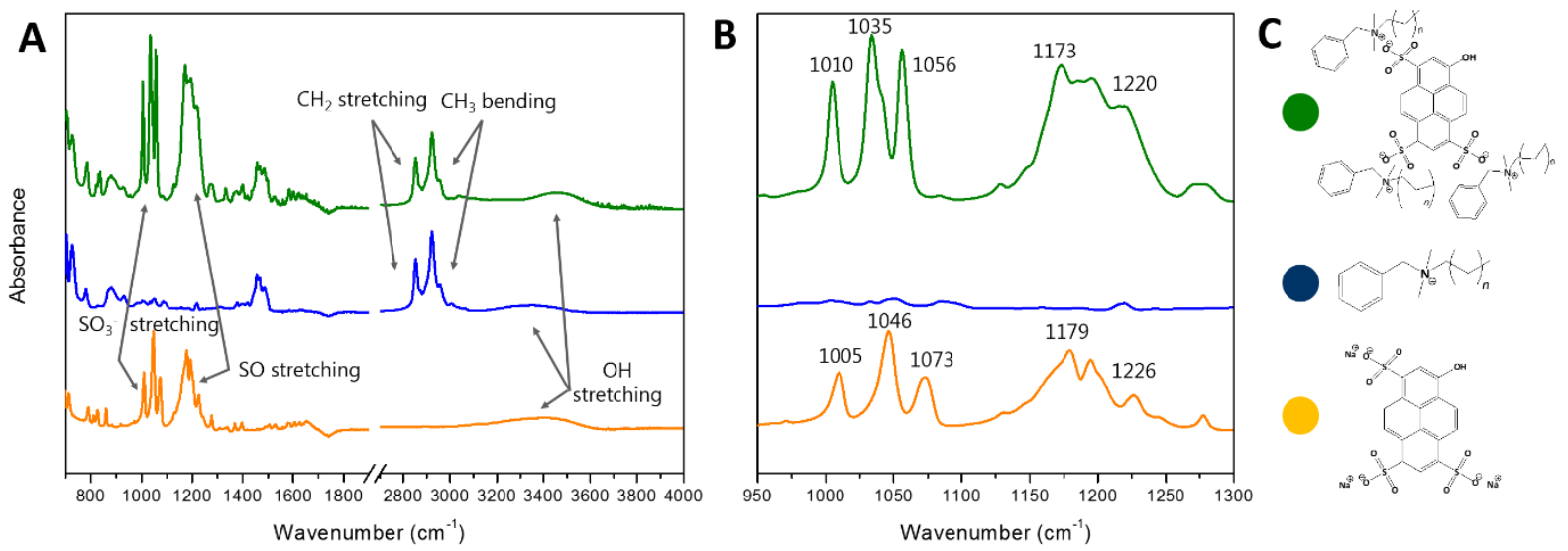

Figure 1. ATR-FTIR spectra of HPTS (yellow), BZKC (blue) and HPTS-BZK (green) ion pair (a) and its magnification on the spectral region $\left.950-1300 \mathrm{~cm}^{-1}, \mathrm{~b}\right)$ along with their molecular structures and color legend (c).

The UV-visible absorption spectrum of the HPTS-BZK ion pair in ethanol is shown in Figure 2A. The absorption maximum of this compound is at $404 \mathrm{~nm}$ with an extinction coefficient $\varepsilon=2.5 \times 10^{4} \mathrm{M}^{-1} \mathrm{~cm}^{-1}$, which is in accordance with reported values for pure HPTS [29]. In presence of a base, such as $\mathrm{NaOH}$, the absorption maximum is shifted to $456 \mathrm{~nm}$. Excitation at these wavelengths resulted in emissions at $436 \mathrm{~nm}$ and $514 \mathrm{~nm}$, respectively (Figure 2B).
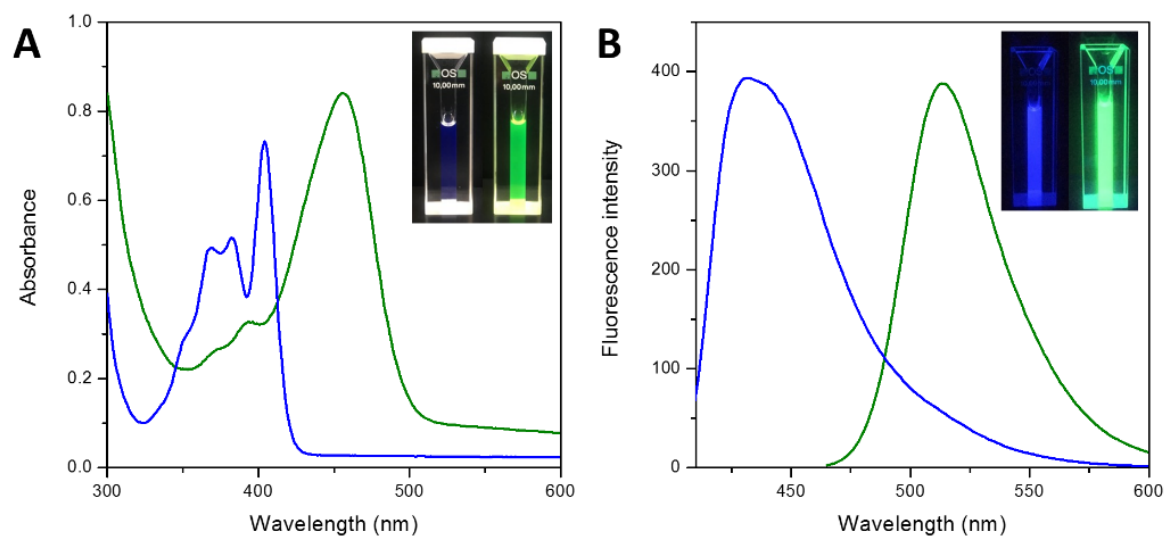

Figure 2. UV-Visible absorption spectra (A) and fluorescence spectra (B) of the HPTS-BZK ion pair in ethanol in absence (blue line) and in presence (green line) of $0.1 \mathrm{M} \mathrm{NaOH}$. The concentrations used for the absorbance and fluorescence measurements were $0.1 \mathrm{mg} \mathrm{mL}^{-1}$ and $0.025 \mathrm{mg} \mathrm{mL}^{-1}$, respectively.

\section{Test of pH-responsiveness of the HPTS-BZK ion pair}

Immobilization of the ion pair on a solid substrate was achieved by drop-casting $50 \mu \mathrm{L}$ of a $15 \mathrm{mg} \mathrm{mL}^{-1}$ HPTS-BZK solution in absolute ethanol directly on poly(vinylidene fluoride) (PVDF) 
membranes followed by solvent evaporation (in air or under vacuum). The morphology of the membranes was not affected by the treatment, as shown by electron microscopy images (see Supplementary information, Figure S1). Commercial cotton-based wound dressings were also evaluated as substrates to demonstrate the proof-of-concept for future application (see Supplementary information, Figure S2).

Chronic wounds, including pressure ulcers, diabetic foot ulcers and venous ulcers, exhibit a varying degree of exudate production depending on several factors (e.g. wound size and stage of healing) [31,32]. In general, wound fluid is rich in electrolytes and phosphate-buffered saline (PBS, pH 7.5; composition: $10 \mathrm{mM} \mathrm{Na} 2 \mathrm{HPO}_{4}, 1.8 \mathrm{mM} \mathrm{KH}_{2} \mathrm{PO}_{4}, 137 \mathrm{mM} \mathrm{NaCl}, 2.7 \mathrm{mM} \mathrm{KCl}$ ) has already been proposed to mimic wound exudate for the testing of wound pads [32]. Solutions with different $\mathrm{pH}$ values, ranging from 5.5 to 8.5 , were prepared by adjusting the $\mathrm{pH}$ of the buffer with aqueous $\mathrm{HCl}$ and $\mathrm{NaOH} 1 \mathrm{M}$ solutions. Given the high ionic strength $I$ of phosphate buffer saline $(I=187$ mmol kg-1 , calculated using the equation $I=1 / 2 \sum m B z B^{2}$, where $m B$ is the molality of ion $B$ and $z B$ is its charge), the overall change associated by $\mathrm{pH}$ adjusting was considered to be negligible for our study, in accordance with other literature protocols [33]. The membranes with immobilized ion pairs were tested at various $\mathrm{pH}$ values by using the supra-mentioned buffer, and the emission intensity at $511 \mathrm{~nm}$ for excitation at both 405 and $460 \mathrm{~nm}$ after $1 \mathrm{~min}$ was recorded (Figure 3A and 3B). The ratio between the intensity of emission after excitation at $405 \mathrm{~nm}\left(\mathrm{I}_{405}\right)$ and after excitation at $460 \mathrm{~nm}\left(\mathrm{I}_{460}\right)$ was calculated and plotted vs. the corresponding $\mathrm{pH}$ value. A corresponding sigmoidal curve was obtained, which allows an efficient discrimination between different $\mathrm{pH}$ values in a range relevant for chronic wounds (i.e. 5.5-7.5).

Compared to state-of-the-art, single-use sensors, our system presents many advantages: the materials used are non-toxic and cytocompatible, the chemicals and the synthetic process themselves are easy to handle. It is noteworthy to state that ethanol is low-class toxicity solvent according to ICH guide solvent list. Moreover, one typical problem exhibited by dye-loaded $\mathrm{pH}$ sensors is that of leaching, i.e. loss of the indicator due to desorption from the matrix. Thanks to the use of a ratiometric detection approach, leaching of the dye is less likely to affect the sensor's performance. In our case, leaching could even be advantageous because it would result in a release of benzalkonium, a powerful antimicrobial agent. Therefore, such sensor attains a reproducible $\mathrm{pH}$ calibration. 

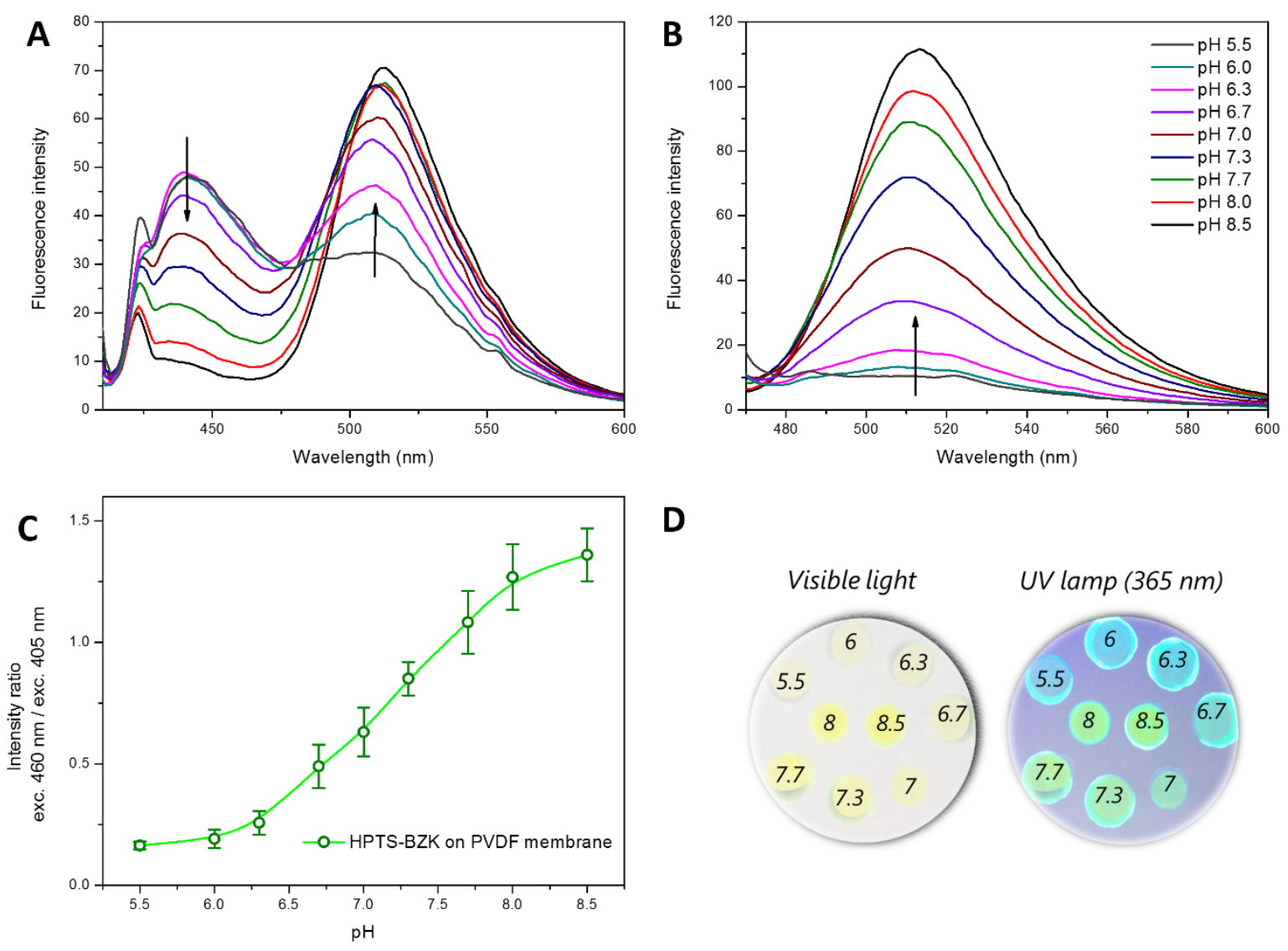

D

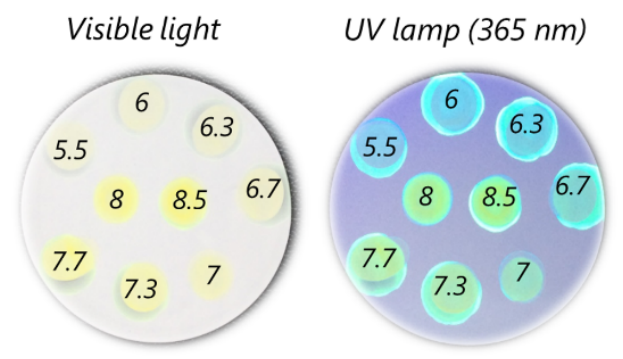

Figure 3. Emission spectra of the HPTS-BZK immobilized on PVDF membrane as a function of $\mathrm{pH}$, obtained with (A) $\lambda_{\mathrm{exc}}=405 \mathrm{~nm}$ and (B) $\lambda_{\mathrm{exc}}=460 \mathrm{~nm}$. The resulting calibration line (average of measurements of three different membranes) (C) is the ratio between the emission at $511 \mathrm{~nm}$ for two different excitation wavelength (i.e. $405 \mathrm{~nm}$ and $460 \mathrm{~nm}$ ). The color change of the immobilized ion pair as a function of $\mathrm{pH}$ is depicted in (D) under both visible and UV light.

\section{Test of antimicrobial properties of the HPTS-BZK ion pair}

In a next step, the HPTS-BZK ion pair was assessed for its antimicrobial activity against methicillin-resistant pathogenic bacteria $S$. aureus. Since HPTS-BZK is not water soluble, it was coated onto a silicon wafer (see the Supplementary Information). After $2 \mathrm{~h}$ incubation of the different surfaces with $S$. aureus cells at $10^{5}$ colony-forming unit (CFU) per mL, the HPTS-BZK coated surface killed all applied $S$. aureus cells, whereas the silicon control surface did not exhibit antimicrobial activity and allowed almost $100 \%$ recovery of the applied cells (Figure 4 ). Thus, the HPTS-BZK ion pair prepared in this work possesses excellent antimicrobial property. 


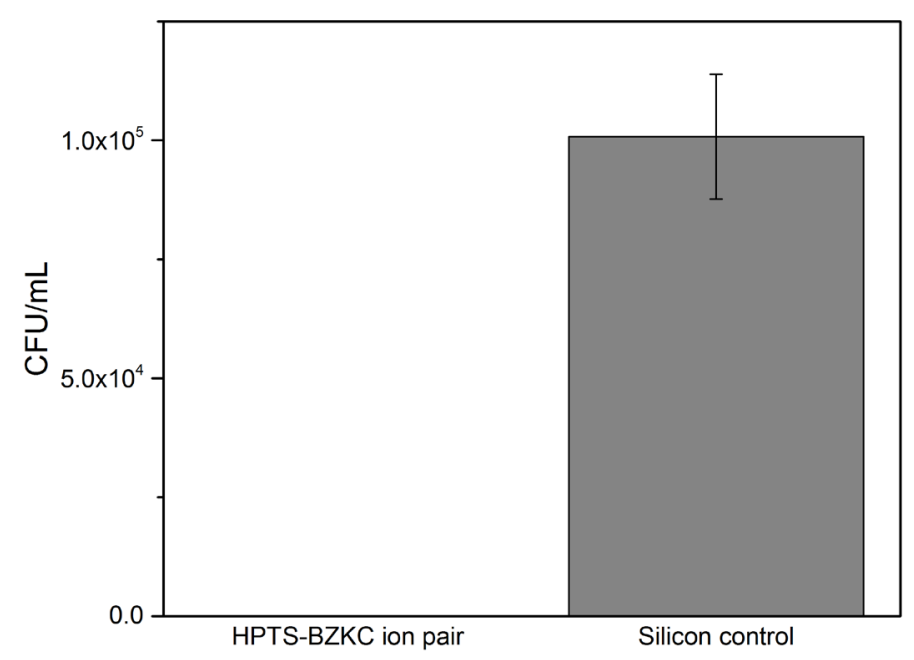

Figure 4. Antimicrobial property of the HPTS-BZK ion pair against $S$. aureus. The data generated from two independent experiments are expressed as the average \pm standard deviation $(\mathrm{N}=6)$.

\section{CONCLUSIONS}

We described the synthesis of a new ion pair between pyranine and benzalkonium (HPTSBZK) and its use in detecting the $\mathrm{pH}$ values in wounds as key bio-marker of wound status via colorimetric and fluorescence intensity calibration in a ratiometric mode. The well-documented non-toxicity of both precursors as well as the deposition solvent makes this sensor particularly appealing for its embedment in biomedical devices. Although the leaching of pyranine is a stringent issue in several ion pair mixtures due to the scarce resistance of the ion pair to ionic strength, the up-scalable and low cost physical entrapment in PVDF filter as well as cotton-based pads via dropcasting paves the way for a direct integration of the sensing units in commercial wound pads.

The $\mathrm{pH}$ calibration range is perfectly suitable for the detection of wound $\mathrm{pH}$ (i.e. 5.5-7.5) even in the presence of ionic buffers, such as PBS saline media. Moreover, we found that for $\mathrm{pH}$ values higher than 7 there is a striking change of the absorbance and the fluorescent emission color, which can be easily evaluated by using a commercial UV LED lamp. Semiquantitative results could be obtained by the aid of a smartphone camera as spectrometer [34]. This would give the patient/nurse/clinician the tools for the discrimination of the wound status, even in the absence of a canonical ratiometric detection apparatus. This would be very important especially for selfmonitoring at home or for dedicated services.

In conclusion, the pyranine-benzalkonium ion pair appears to be a promising candidate for the development of point-of-care wound diagnostics sensors. 


\section{ACKNOWLEDGMENTS}

This work was funded by Nano-Tera.ch via the project FlusiTex-Gateway. The authors acknowledge the technical support of Stefanie Altenried.

\section{REFERENCES}

[1] C. K. Sen, G. M. Gordillo, S. Roy, R. Kirsner, L. Lambert, T. K. Hunt, F. Gottrup, G. C. Gurtner, M. T. Longaker, Human skin wounds: A major and snowballing threat to public health and the economy, Wound Rep Reg 17 (2009) 763-771.

[2] T. R. Dargaville, B. L.Farrugia, J. A. Broadbent, S. Pace, Z. Upton, N. H. Voelcker, Sensors and imaging for wound healing: A review, Biosensors and Bioelectronics 41 (2013) 30-42.

[3] A. McLister, J. McHugh, J. Cundell, J. Davis, New Developments in Smart Bandage Technologies for Wound Diagnostics, Adv. Mater. (2016), 1-6.

[4] L. A. Schneider, A. Korber, S. Grabbe, J. Dissemond, Influence of pH on wound-healing: a new perspective for wound-therapy? Arch. Dermatol. Res 298 (2007) 413-420.

[5] S. L. Percival, S. McCarty, J. A. Hunt, E. J. Woods, The effects of $\mathrm{pH}$ on wound healing, biofilms, and antimicrobial efficacy, Wound Rep. Reg. 22 (2014) 174-186.

[6] G. Gethin, The significance of surface $\mathrm{pH}$ in chronic wounds, Wounds UK 3 (2007) 52-56.

[7] S. Ono, R. Imai, Y. Ida, D. Shibata, T. Komiya, H. Matsumura, Increased wound pH as an indicator of local wound infection in second degree burns, Burns 41 (2015) 820-824.

[8] G. Rao (Ed.), Optical Sensor Systems in Biotechnology, Springer Science \& Business Media, 2009.

[9] S. Widmer, M. Dorrestijn, A. Camerlo, S. K. Urek, A. Lobnik, C. E. Housecroft, E. C. Constable, L. J. Scherer, Coumarin meets Fluorescein: A Förster Resonance Energy Transfer enhanced optical Ammonia Gas Sensor. Analyst 139 (2014), 4335-4342.

[10] S. Widmer, M. J. Reber, P. Müller, C. E. Housecroft, E. C. Constable, R. M. Rossi, D. Brühwiler, L. J. Scherer, L. F. Boesel, On the Incorporation of a FRET Dye Pair into Mesoporous Materials: a Comparison in Fluorescence Spectra, FRET Activity and Dye Accessibility. Analyst 140 (2015), 5324-5334.

[11] D. Jankowska, M. Bannwarth, C. Schulenburg, G. Faccio, K. Maniura-Weber, R. M. Rossi, L. J. Scherer, M. Richter, L. F. Boesel, Simultaneous detection of $\mathrm{pH}$ value and key-metabolite concentrations for wound monitoring applications. Biosens. Bioelectron. 87, (2017), 312-319.

[12] B. Finkler, C. Spies, M. Vester, F. Walte, K. Omlor, I. Riemann, M. Zimmer, F. Stracke, M. Gerhards, G. Jung, Highly photostable "super"-photoacids for ultrasensitive fluorescence spectroscopy. Photochem. Photobiol. Sci. 13, (2014), 548-562.

[13] B. D. MacCraith, C. McDonagh, Enhanced Fluorescence Sensing Using Sol-Gel Materials, Journal of Fluorescence, 12 (2002) 333-342.

[14] N. Wittouck, F. De Schryver, I. Snijkers-Hendrickx, Fluorescence of Pyranine in Sol-Gel Based Silica and Hybrid Thin Films, Journal of Sol-Gel Science and Technology 8 (1997) 895-899.

[15] J.C. Pouxviel, S. Parvaneh, E.T. Knobbe, B. Dunn, Interactions between organic dyes and solgel matrices, Solid State lonics 32/33 (1989) 646-654.

[16] D. Wencel, B. D. MacCraith, C. McDonagh, High performance optical ratiometric sol-gelbased pH sensor, Sensors and Actuators B 139 (2009) 208-213.

[17] C.-S. Chu, Y.-L. Lo, Highly sensitive and linear optical fiber carbon dioxide sensor based on sol-gel matrix doped with silica particles and HPTS, Sensors and Actuators B 143 (2009) 205-210.

[18] C. S. Burke, A. Markey, R. I. Nooney, P. Byrne, C. McDonagh, Development of an optical sensor probe for the detection of dissolved carbon dioxide, Sensors and Actuators B 119 (2006) 288-294. 
[19] R. N. Dansby-Sparks, J. Jin, S. J. Mechery, U. Sampathkumaran, T. W. Owen, B. D. Yu, K. Goswami, K. Hong, J. Grant, Z.-L. Xue, Fluorescent-Dye-Doped Sol-Gel Sensor for Highly Sensitive Carbon Dioxide Gas Detection below Atmospheric Concentrations, Anal. Chem. 82 (2010) 593-600.

[20] G. J. Mohr, T. Werner, I. Oehme, C. Preininger, 1. Klimant, B. Kovacs, O. S. Wolfbeis, Novel Optical Sensor Materials Based on Solubilization of Polar Dyes in Apolar Polymers, Adv. Mater. 9 (1997) 1108-1113.

[21] Z. Zhujun, R. W. Seitz, A fluorescence sensor for quantifying $\mathrm{pH}$ in the range from 6.5 to 8.5 , Anal. Chim. Acta, 160 (1984) 47-55.

[22] J. Han, K. Burgess, Fluorescent indicators for intracellular pH, Chem. Rev., 110 (2010) 27092728.

[23] T. Werner, I. Klimant, O S. Wolfbeis, Ammonia-sensitive Polymer Matrix Employing Immobilized Indicator Ion Pairs Analyst, 120 (1995) 1627-1631.

[24] G. McDonnell, A. D. Russell, Antiseptics and disinfectants: activity, action, and resistance. Clinical Microbiology Reviews, 12 (1999) 147-179.

[25] B. Marple, P. Roland, M. Benninger, Safety Review of Benzalkonium Chloride Used as a Preservative in Intranasal Solutions: An Overview of Conflicting Data and Opinions, Otolaryngol. Head Neck Surg. 130 (2004) 131-141.

[26] E. B. Walker, Quaternary ammonium compounds, chapter 5 (pagg. 99-116) in: D. S. Paulson (Ed.), Handbook of Topical Antimicrobials: Industrial Applications in Consumer Products and Pharmaceuticals, CRC Press, 2002, 464 pagg.

[27] R. Barnadas-Rodríguez, J. Cladera, Steroidal Surfactants: Detection of Premicellar Aggregation, Secondary Aggregation Changes in Micelles, and Hosting of a Highly Charged Negative Substance, Langmuir 31 (2015) 8980-8988.

[28] K. Liu, X. Lin, L. Chen, L. Huang, S. Cao, H. Wang, Preparation of Microfibrillated Cellulose/Chitosan-Benzalkonium Chloride Biocomposite for Enhancing Antibacterium and Strength of Sodium Alginate Films, J. Agric. Food Chem. 61 (2013) 6562-6567.

[29] E. A. Legenzov, N. D. A. Dirda, B. M. Hagen, J. P. Y. Kao, Synthesis and Characterization of 8-O-Carboxymethylpyranine (CM-Pyranine) as a Bright, Violet-Emitting, Fluid-Phase Fluorescent Marker in Cell Biology, PLoS ONE, 10 (2015) e0133518.

[30] N. L. Zhou, N. Meng, Y. C. Ma, X. G. Liao, J. Zhang, L. Li, J. Shen, Evaluation of antithrombogenic and antibacterial activities of a graphite oxide/heparin-benzalkonium chloride composite. Carbon 47 (2009), 1343-1350.

[31] C. Dowsett, Exudate management: a patient-centred approach. J. Wound Care 6 (2008), 249252.

[32] J. B. Lutz, C. L. Zehrer, S. E. Solfest, S.-A. Walters, A New In vivo Test Method to Compare Wound Dressing Fluid Handling Characteristics and Wear Time. Ostomy Wound Management 8 (2011), 28-36.

[33] Y. Avnir, Y. Barenholz, $\mathrm{pH}$ determination by pyranine: Medium-related artifacts and their correction. Anal. Biochem. 347 (2005), 34-41.

[34] H. Yu, Y. Tan, B. T. Cunningham, Smartphone Fluorescence Spectroscopy. Anal. Chem. 86 (2014), 8805-8813. 